\title{
Evolutionary history of species of the firefly subgenus Hotaria (Coleoptera, Lampyridae, Luciolinae, Luciola) inferred from DNA barcoding data
}

\author{
Taeman Han \\ Applied Entomology Division, Department of Agricultural Biology, National \\ Institute of Agricultural Science, Nongsaengmyeong-ro 166, Iseo-myeon, \\ Wanju- gun, Jeollabuk-do 55365, Korea \\ Seung-Hyun Kim \\ Applied Entomology Division, Department of Agricultural Biology, National \\ Institute of Agricultural Science, Nongsaengmyeong-ro 166, Iseo-myeon, \\ Wanju- gun, Jeollabuk-do 55365, Korea \\ Hyung Joo Yoon \\ Applied Entomology Division, Department of Agricultural Biology, National \\ Institute of Agricultural Science, Nongsaengmyeong-ro 166, Iseo-myeon, \\ Wanju- gun, Jeollabuk-do 55365, Korea \\ In Gyun Park \\ Applied Entomology Division, Department of Agricultural Biology, National \\ Institute of Agricultural Science, Nongsaengmyeong-ro 166, Iseo-myeon, \\ Wanju- gun, Jeollabuk-do 55365, Korea \\ Haechul Park \\ Applied Entomology Division, Department of Agricultural Biology, National \\ Institute of Agricultural Science, Nongsaengmyeong-ro 166, Iseo-myeon, \\ Wanju- gun, Jeollabuk-do 55365, Korea \\ culent@korea.kr
}

\begin{abstract}
The firefly subgenus Hotaria sensu lato of the genus Luciola currently includes four morphospecies: $L$. $(H$.) parvula, $L$. (H.) unmunsana, $L(H$.) papariensis, and $L$. $(H$.) tsushimana. The latter three are taxonomically controversial based on both morphological and molecular data. We examined the phylogenetic relationships and evolutionary history of the species and related congeners using partial COI gene sequences (DNA barcoding). Our phylogenetic analyses consistently supported the monophyly of Hotaria sensu lato, but did not resolve the generic rank. The two types of $L$. $(H$.) parvula in Japan can be considered distinct


species that arose by pseudocryptic speciation during the Miocene, with substantial genetic divergence (15.41\%). Three morphospecies, L. (H.) unmunsana, $L$ (H.) papariensis, and L. (H.) tsushimana, split into several polyphyletic or paraphyletic groups, forming entangled species groups. They are considered an incipient group that is distinguishable genetically but not morphologically, with evidence for recent allopatric speciation events corresponding to geologic events and sea-level changes during the Pliocene and Pleistocene. Group III of $L$. (H.) unmunsana collected from the Jeolla region is a new taxon.

\section{Keywords}

Fireflies - Luciola - Hotaria - incipient species diversity - molecular clock - allopatric speciation

\section{Introduction}

Fireflies belonging to the family Lampyridae may be the most charismatic among all insects owing to their beautiful light signals for spectacular courtship displays. Thus, they have inspired many poems, songs, and stories as well as research. Fireflies include more than 2,000 species in 100 genera (Lewis \& Cratsely, 2008). Six species in five genera and two subfamilies are known in Korea (Kang, 2012). In the genus Luciola of Luciolinae, three species are recognized in Korea. $L$. (s. str.) lateralis is morphologically distinct from the other two Korean species, L. (Hotaria) unmunsana and L. (H.) papariensis, based on its black scutellum and large punctures on the pronotum. However, L. (H.) unmunsana and L. (H.) papariensis are highly similar to each other.

Doi (1931, 1932) described L. unmunsana (type locality: Mt. Unmun, Cheongdo-gun, Gyeongsangbuk-do, South Korea) and L. papariensis (type locality: Pabalri, Pungsan-gun, Hamgyeongnam-do, North Korea). The color pattern of the pronotum, which is orangered in L. (H.) unmunsana and yellowishbrown with blackish semicircular speckle at the anterior part in L. (H.) papariensis, is a diagnostic character (Doi, 1931, 1932). However, the type specimens were lost and accordingly cannot be examined to confirm the morphological differentiation. Previous studies of the distributional patterns of the two Korean Luciola species are based on the descriptions by Doi (1931, 1932). Kim \& Nam (1981) reported that $L$. $(H$.$) papariensis$ is dominant in the northern part and $L .(H$. unmunsana is abundant in the southern part of South Korea. Sim \& Kwon (2000) obtained similar results but found that the two species are sympatric at every site surveyed, except for a remote volcanic Island, Jeju, where only $H$. (H.) unmunsana is found. Kim et al. (2004) suggested that L. (H.) papariensis and L. $(H$.) unmunsana are not different species because the remarkable the pronotal semicircular speckle is polymorphic within species and sometimes differ between species. Kang (2012) also pointed out that $L$. $(H$.) papariensis may be the same as $L$. $(H$.$) unmunsana$ or at least may not be distributed in South Korea based on topotypical specimens of $L$. unmunsana collected from the type locality, Mt. Unmun, with the blackish semicircular speckle on the pronotum. This conclusion was based on the description of Doi (1932), which did not consider intraspecific variation in the pronotal speckle. Closely related species, similar to the two Korean species of Luciola, are also found in Japan. L. (H.) tsushimana Nakane, 1970 is distributed only on Tsushima Is. and L. (H.) parvula Kiesenwetter, 
1874 is widely found on three major islands (Honshu, Shikoku, and Kyushu).

These four morphospecies are currently classified in the subgenus Hotaria Yuasa, 1937 of the genus Luciola (Sim et al., 1999; Sim \& Kwon, 2000; Suzuki, 2001), but the taxonomic position of Hotaria is still unclear. It has been treated as a genus (Yuasa, 1937; Nakane \& Ohba, 1981; Kurosawa et al., 1985; Hirashima, 1989; Suzuki, 1997; Ohba, 1998; Choi et al., 2002), as a subgenus (McDermott, 1966; Ballantyen, 1968; Suzuki, 2001), and as synonymous with Luciola (Oba et al., 2011).

During the past two decades, Korean and Japanese fireflies in Luciola have been investigated extensively using molecular approaches (see reviewed by Suzuki, 2001; Kim et al., 2004). Suzuki et al. (1993) used 13 allozyme loci to analyze populations of Hotaria parvula, which can be distinguished into two types according to male body size, the dimorphism of flash interval patterns in males, and their allopatric distribution in Japan (Ohba, 1983, 1986, 1987), and found two genetically distinct ecological types. Ohmiya et al. (1995) found that H. parvula is separated from Luciola lineages, including L. cruciata and L. lateralis, in an analysis of luciferase amino acid sequences. Suzuki (1997) examined a partial sequence of mitochondrial 16S ribosomal RNA (16S rRNA) and showed $H$. parvula and $H$. tsushimana form a monophyletic group that is separated from other $L u$ ciola species. Kim et al. (2004) analyzed luciferase and mitochondrial DNA sequences and found that $H$. papariensis, $H$. unmunsana, and H. tsushimana do not exhibit sufficient divergence to be considered separate species (Kim et al., 2000; Choi et al., 2002, 2003). However, they used only a few local samples (<five specimens). Therefore, the precise species statuses of these species are unclear.

In this study, we performed a DNA barcoding analysis using COI gene sequences to evaluate larger sample sizes of Luciola (Hotaria) papariensis and L. (H.) unmunsana. Our findings clarify the species statuses of four congeners in Hotaria and provide insight into intraand interspecific divergence.

\section{Material and methods}

\section{Taxon sampling and initial morphospecies identification}

In total, 72 specimens regarded as Luciola (Hotaria) papariensis and L. (H.) unmunsana were collected in South Korea. This additional sampling was expected to provide more improved species identification and genetic structures for the focal taxa by expanding on the locations and sample sizes than the previous studies. These samples were kept alive until they could be stored at $-80^{\circ} \mathrm{C}$ for DNA extraction. For morphospecies identification, the descriptions of Doi $(1931,1932)$ were used owing to the lack of type specimens. The general features of the specimens were observed under a stereoscopic microscope (MZ $16 \mathrm{~A}$ and MZ 6; Leica, Solms, Germany). L. (H.) papariensis was identified based on the presence of the black semicircular speckle on the anterior part of the pronotum and $L$. (H.) unmunsana lacked the speckle on the pronotum. Finally, 22 specimens were identified as $L$. $(H$. $)$ papariensis from five localities, mainly in the northern part of South Korea, and 50 specimens were recognized as $L$. $(H$.) unmunsana from five localities, mainly in the middle to southern parts of South Korea (table 1, supplementary table S1). Unlike previous studies (Kim \& Nam, 1981; Sim \& Kwon, 2000; Kim et al., 2004; Kang, 2012), we did not find these two species co-occurring at the same collecting sites. All materials were preserved in the insect collection at the Applied Entomology Division, Department of Agricultural Biology, National Institute of Agricultural Science (NIAST), Jeonju, Korea. 
TABLE 1 Summary of the firefly species examined in this study

\begin{tabular}{|c|c|c|c|c|c|}
\hline \multirow[t]{2}{*}{ Species ID } & \multirow[t]{2}{*}{ Species } & \multirow[t]{2}{*}{ Samplesize } & \multirow{2}{*}{$\begin{array}{l}\text { Collection } \\
\text { localities }\end{array}$} & \multicolumn{2}{|c|}{ Source of COI sequences } \\
\hline & & & & Present study & $\mathrm{NCBI}$ \\
\hline 1 & $\begin{array}{l}\text { Luciolar (Hotaria) } \\
\text { unmunsana Doi, } 1931\end{array}$ & 54 & South Korea $(54)^{*}$ & $\circ$ & $\circ$ \\
\hline 2 & $\begin{array}{l}\text { Luciolar (Hotaria) } \\
\text { papariensis Doi, } 193^{2}\end{array}$ & 25 & South Korea $(25)^{*}$ & $\circ$ & $\circ$ \\
\hline 3 & $\begin{array}{l}\text { Luciolar (Hotaria) } \\
\text { tsushimana Nakane, } 1970\end{array}$ & 4 & Japan (4) & & $\circ$ \\
\hline 4 & $\begin{array}{l}\text { Luciola (Hotaria) parvula } \\
\text { Kiesenwetter, } 1874\end{array}$ & 5 & Japan (5) & & $\circ$ \\
\hline 5 & $\begin{array}{l}\text { Luciola italica } \\
\text { (Linnaeus, 1767) }\end{array}$ & 2 & $\begin{array}{l}\text { Germany (1), } \\
\text { Slovenia (1) }\end{array}$ & & $\circ$ \\
\hline 6 & $\begin{array}{l}\text { Luciola lateralis } \\
\text { Motschulsky, } 1860\end{array}$ & 26 & $\begin{array}{l}\text { South Korea }(24)^{*}, \\
\text { Japan }(2)\end{array}$ & $\circ$ & $\circ$ \\
\hline 7 & $\begin{array}{l}\text { Luciola cruciata } \\
\text { Motschulsky, } 1854\end{array}$ & 5 & Japan (5) & $\circ$ & $\circ$ \\
\hline 8 & $\begin{array}{l}\text { Luciola curtithorax Pic, } \\
1928\end{array}$ & 1 & China (1) & & $\circ$ \\
\hline 9 & $\begin{array}{l}\text { Luciola filiformis yayeya- } \\
\text { mana= L. yayeyamana } \\
\text { Matsumura, } 1918 \text { (in } \\
\text { Suzuki, 2011) }\end{array}$ & 1 & Japan (1) & & $\circ$ \\
\hline 10 & Luciola sp. & 1 & Taiwan (1) & & $\circ$ \\
\hline 11 & $\begin{array}{l}\text { Luciola substriata } \\
\text { Gorham, } 1880\end{array}$ & 1 & Unknown (1) & & $\circ$ \\
\hline 12 & $\begin{array}{l}\text { Aquatica wuhana Fu, } \\
\text { Ballantyne and Lambkin, } \\
2010\end{array}$ & 1 & China (1) & & $\circ$ \\
\hline 13 & $\begin{array}{l}\text { Lucidina kotbandia } \\
\text { Park and Kang, 2005 } 5^{\dagger}\end{array}$ & 1 & South Korea $(1)^{*}$ & $\circ$ & \\
\hline 14 & $\begin{array}{l}\text { Pyrocoelia rufa (Olivier, } \\
\text { 1886) (larva) }\end{array}$ & 1 & South Korea $(1)^{*}$ & $\circ$ & \\
\hline
\end{tabular}

* indicates that Korean specimens were included. ${ }^{\dagger}$ indicates that the species was used as an outgroup.

\section{DNA barcoding}

Genomic DNA was isolated from genital tissues using a QIAamp DNA Mini Kit (Qiagen, Hilden, Germany). To protect the genital structures, tissues were not pulverized but were only soaked in lysis buffer for 12 hours.
PCR was performed using AccuPower Profi Taq PCR PreMix (Bioneer, Daejeon, Korea) with the universal primer set LCO149o/ HCO2198 (Folmer et al., 1994). The PCR conditions, processing of PCR amplicons, sequencing, and checking for co-amplified paralogous 
sequences and contaminants are described in our previous study (Han et al., 2019).

For comparative analyses, 54 COI sequences for 12 Luciola species were downloaded from GenBank (http://www.ncbi.nlm.nih .gov/genbank) (Kim et al., 2001; Choi et al., 2003; Stanger-Hall et al., 2007; Oba et al., 2011; Amano et al., 2013; Hendrich et al., 2015; $\mathrm{Mu}$ et al., 2016; Maeda et al., 2017; Wang et al., 2017; $\mathrm{Hu} \& \mathrm{Fu}$ 2018; see details in supplementary table S1). Two species in Lampyrinae, Lucidina kotbandia Park \& Kang, 2005 (Photinini) and Pyrocoelia rufa Olivier, 1886 (Lampyrini), were included as outgroup taxa.

COI sequences were aligned using MEGA 5.2 (Tamura et al., 2011) and ClustalW and the alignment was manually checked by searching for stop codons and potential frameshifts in the translated amino acid sequences. A dataset consisting of 128 COI sequences was finally trimmed to $65^{8} \mathrm{bp}$ in length: 85 sequences in full length; five in $613-657 \mathrm{bp}$; 15 in 421 bp; 23 in 403 bp as given in supplementary table S1. COI sequences generated in this study are available in GenBank under accession numbers MK778928-MK779002 and MK78oo66 (supplementary table S1).

\section{Phylogenetic analyses and molecular dating}

For comprehensive phylogenetic analyses to complement results of each tree estimation methods based on a single genetic marker, COI (Holder \& Lewis, 2003), we employed three phylogenetic methods such as distancebased Neighbor-Joining (NJ), optimality criterion-based Maximum Likelihood (ML), and Markov Chain Monte Carlo (MCMC)-based Bayesian analysis. A NJ analysis (Saitou \& Nei, 1987) was performed using MEGA 5.2. Genetic distances were calculated using the Kimura 2-parameter model (Kimura, 1980) in MEGA 5.2. The branch support values of each node were estimated with 1000 bootstrap replicates (Felsenstein, 1985). A ML analysis was performed using the W-IQ-TREE web server (Trifinopoulos et al., 2016). The bestfit model for the molecular evolution of the COI sequence data was $\mathrm{GTR}+\mathrm{F}+\mathrm{I}+\mathrm{G}_{4}(-\mathrm{lnL}=$ 5326.3205 ) based on the Bayesian information criterion, as determined using ModelFinder (Kalyaanamoorthy et al., 2017). Branch support was evaluated by 1000 ultrafast bootstrap (UFBoot) replicates (Mihn et al., 2013; Hoang et al., 2017). A Bayesian phylogenetic analysis (BI) was performed using MrBayes 3.2.5 (Ronquist et al., 2012). Metropolis-coupled MCMC analyses were run with one cold and three heated chains (temperature set to 0.2 ) for 5,000,000 generations, sampling three times every 100 generations. The posterior probabilities were obtained and a majority-rule consensus tree was generated from the remaining trees after discarding the first $25 \%$ of samples.

For molecular dating, reliable fossil records and/or geological events were determined. However, a reliable fossil record was unavailable for the genus Luciola. It was difficult to apply reliable calibration points to specific nodes, even though the initial disconnection of Japan from the mainland $15 \mathrm{Ma}$ and the final disconnection of Japan from the mainland 3.5 Ma are known (Osozawa et al., 2012). For example, the split between Luciola tsushimana and its sister group might not correspond with the complete geological isolation between the southern part of Korea and the northern part of Kyushu, Japan due to frequent sea-level changes from 3.5 Ma to 1.7 Ma. Furthermore, land bridges may have formed three times during glacial periods after 1.7 Ma (Kitamura \& Kimoto, 2006; Osozawa et al., 2012). In this study, a rate of 0.0177 (equal to $3.54 \%$ divergence per Ma) for COI was used for calibration, as the proposed insect molecular clock by Papadopoulou et al. (2010), which has been widely adopted time estimations in many insect taxa (e.g., for Locusta migratoria in Ma et al., 2012; diving beetles in Bergsten etal., 2012; 
freshwater arthropods in Toussaint et al., 2013; forest beetles in Rizvanovic et al., 2019; blister beetles in López-Estrada et al., 2019). The divergence time for each node was calculated using BEAST v.2.4.6 (Bouckaert et al., 2014) under a strict clock with the appropriate nucleotide substitution model for each codon position. Four independent BEAST runs with a Yule tree prior for 100 million generations were performed, sampling parameters every $\mathbf{1 , 0 0 0}$ generations. Stationarity in MCM chains was confirmed using Tracer 1.6 (Rambaut et al., 2014). The log files were combined using LogCombiner (part of the BEAST package), a maximum clade credibility tree with means of node heights was constructed using TreeAnnotator (part of the BEAST package), and the final tree was visualized using FigTree v1.4.4 (http://tree.bio.ed.ac.uk/software/figtree).

\section{Results}

\section{DNA barcoding of morphospecies}

Our combined dataset consisted of 128 COI sequences from 14 morphospecies (table 1, details in supplementary table S1). We did not find evidence for pseudogenes or heteroplasmy. The intra- and interspecific genetic distances are given in fig. 1.

In a $\mathrm{NJ}$ analysis (fig. 1), the four species in the subgenus Hotaria [Luciola (Hotaria) papariensis: LP, endemic to Korea; $L$. $(H$.) unmunsana: LU, endemic to Korea; L. (H.) tsushimana: LT, endemic to Tsushima Is., Japan; $L$. (H.) parvula: LPA, endemic to Japan] clustered as a monophyletic group with strong support (91\%; fig. 1, node A). However, we also detected polyphyletic or paraphyletic lineages. LP was split into two groups in South Korea (fig. 1, nodes D and G). LU clearly formed three different lineages in South Korea (fig. 1, nodes D, F and $G)$. LT was also split into three groups in Tsushima Is., Japan (fig. 1, nodes E and F). LPA was separated in two groups corresponding to the Japanese main islands, a Honshu (Aichi) population and a Shikoku (Omogo) population, with a large genetic distance of $15.41 \%$ (fig. 1, nodes A and B).

Group I of LP (LP I) was clustered with group I of LU (LU I); although LP I and LU I have traditionally been recognized as different morphospecies, they were genetically more closely related to each other than to other groups. Group II of LP (LP II) was a sister group to group II of LU (LU II) collected from Jeju Is. and was related to group I and II of LT (LT I and II). Group III of LU (LU III) was separated from other groups with strong support $(99 \%)$; these specimens only consisted of local populations of Jeollabuk-do (JB) and Jeollanam-do (JN), collectively called the Jeolla region. LT had three distinct haplotypes (LT I, II, and III) in four samples. The COI profile also indicated that the detected groups of each species had genetically differentiated local populations with low genetic distances $(<1.77 \%)$ across localities. LP I showed six local populations were subdivided within $1.45 \%$ of the maximum intraspecific genetic distance. Two local populations (Cheongdo, GB and Busan, GN) of LU I were subdivided within $0.96 \%$ genetic distances. Two local populations (Yangyang and Donghae) of LP II were separated genetically ranging $0.15 \%-1.08 \%$. Five local populations (Muju, Wanju, Seunchang, Jinan, Jangseong) of LU III showed three subdivisions, except for specimens collected at Mt. Hiemun, Seunchang and Mt. Baekyang, Jangseong which were in close proximity.

\section{Phylogenetic analyses}

The ML (fig. 2) and NJ tree topologies were similar, with differences in the sister relationships for Aquatica wuhana, Luciola substriata, and L. italica. The subgenus Hotaria was well supported (93\%; fig. 2, node A), but 


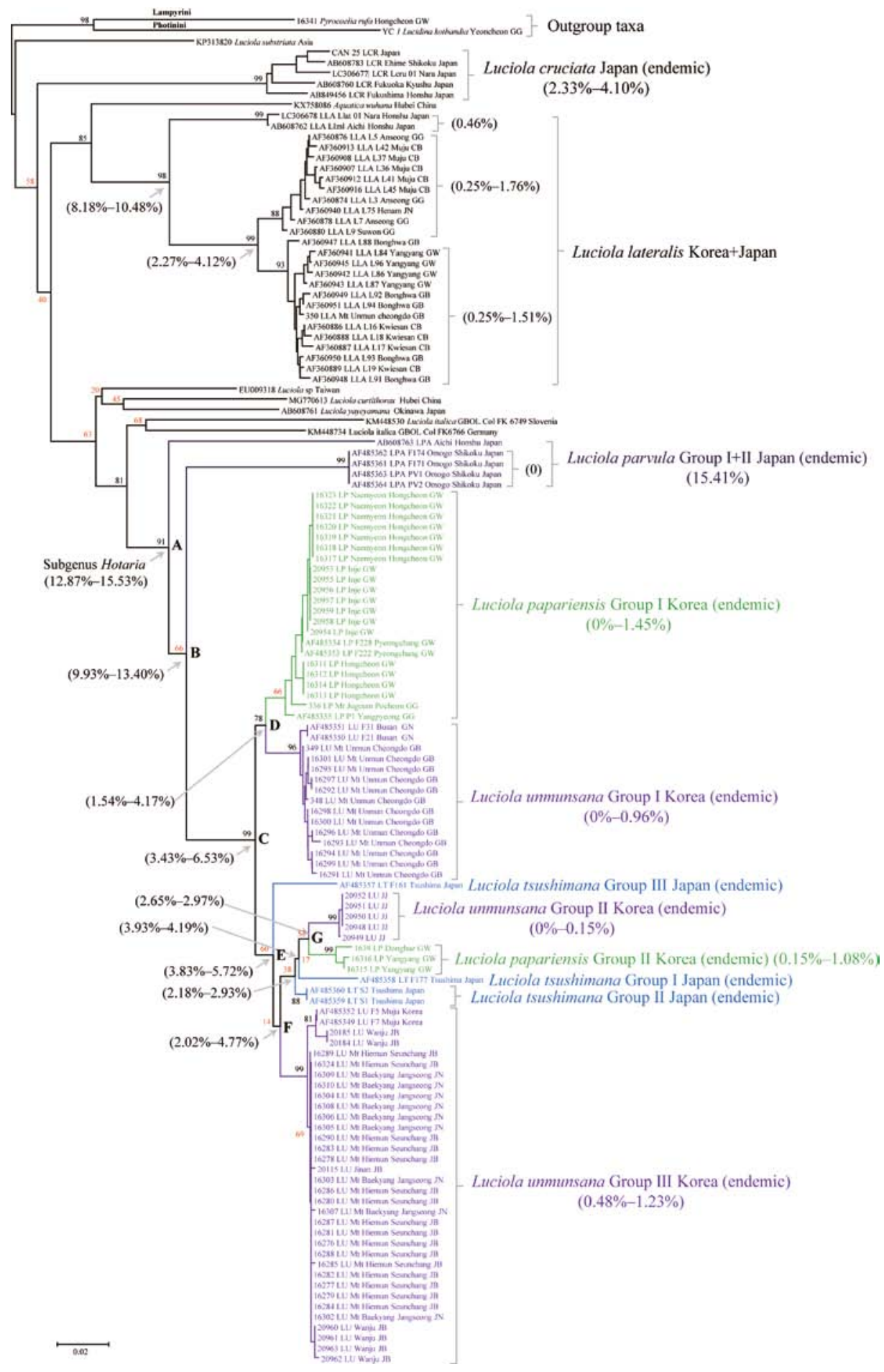

FIGURE 1 Neighbor-joining (NJ) tree of 128 samples of 14 morphospecies based on COI barcode sequences. The percentages at terminal taxa indicate intraspecific genetic divergence. The percentages at each node indicate genetic divergence for the split. Weakly supported nodes (bootstrap values below 70\%) are shown in red. 


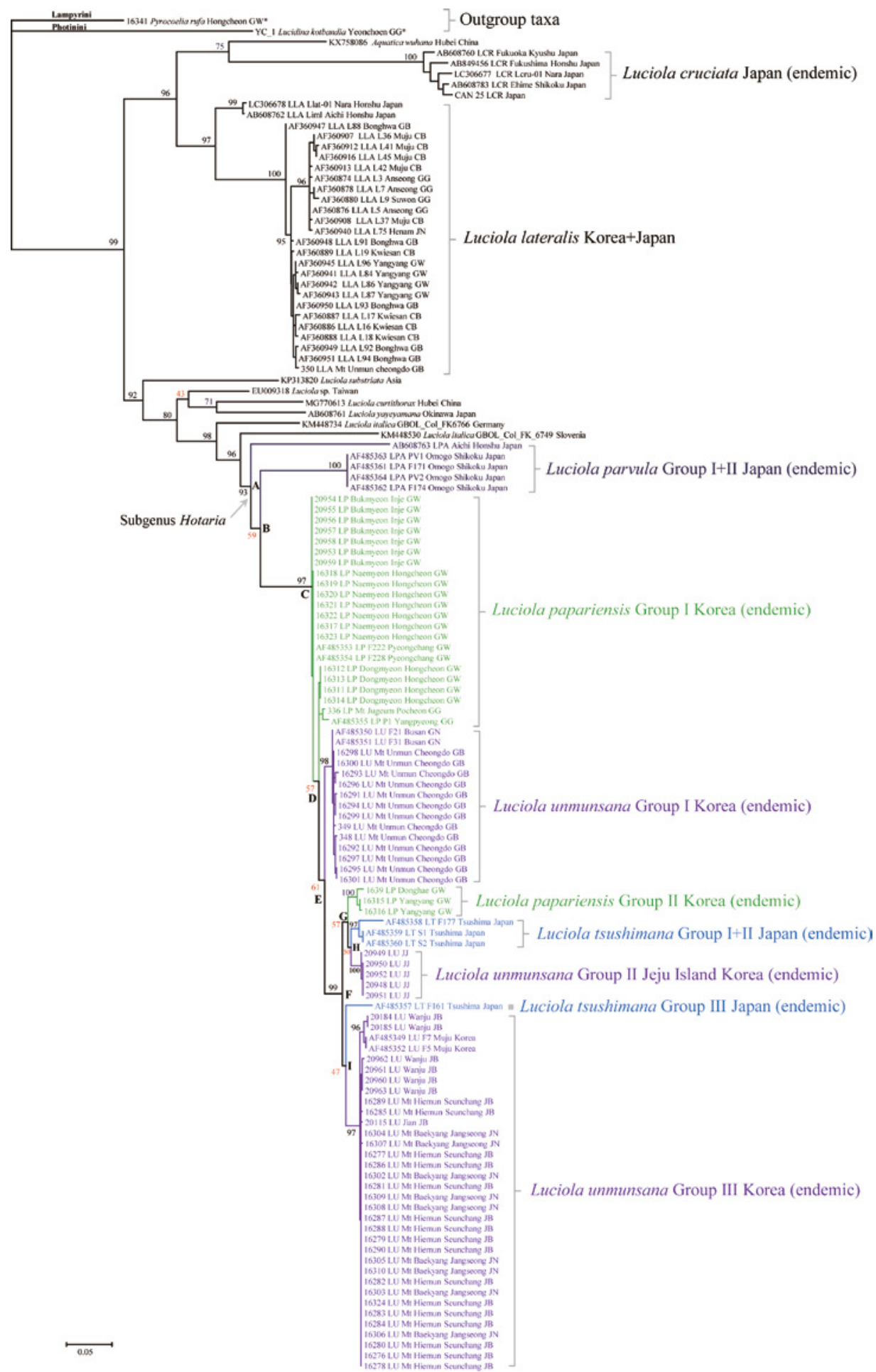

FIGURE 2 Maximum likelihood (ML) tree of 128 samples of 14 morphospecies based on COI barcode sequences. The numbers at each node indicate support (\%). Weakly supported nodes (below $70 \%$ ) are shown in red. 


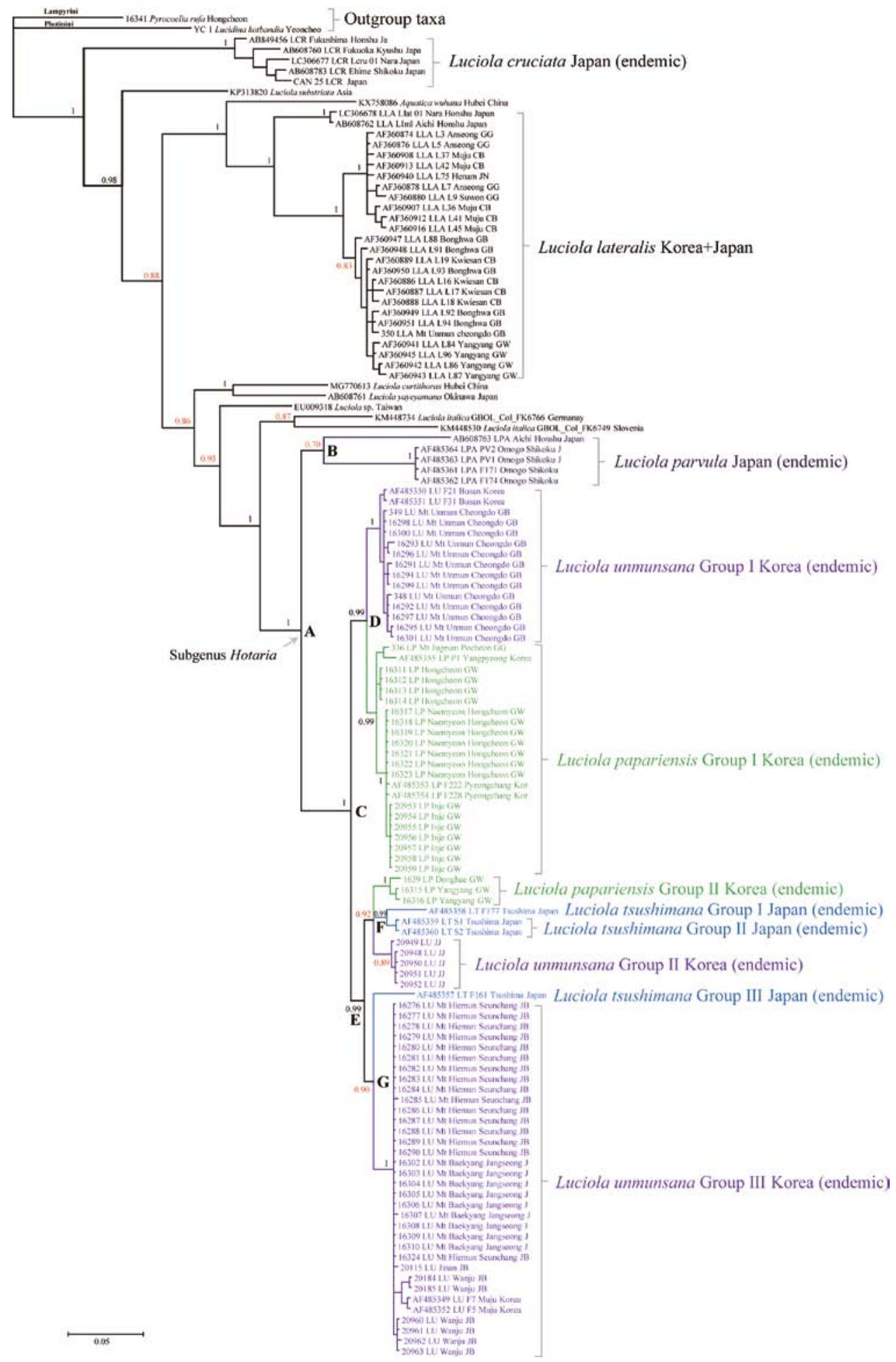

FIGURE 3 Majority-rule consensus tree from a Bayesian analysis (BI) of 128 samples of 14 morphospecies based on COI barcode sequences. The numbers at each node indicate posterior probabilities. Weakly supported nodes (posterior probability below 0.95) are shown in red. 


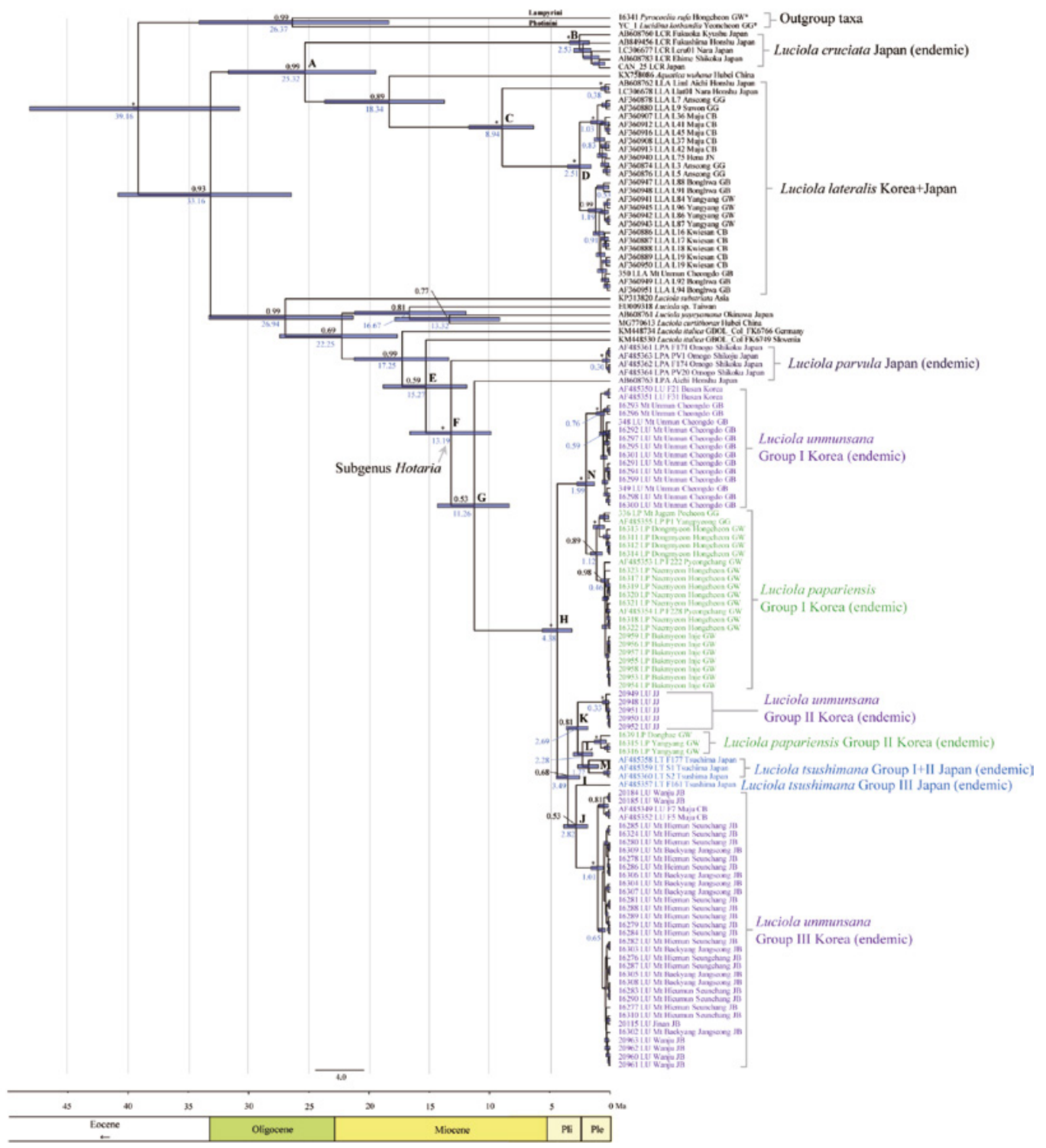

FIGURE 4 Time-calibrated phylogram calculated using BEAST based on the COI dataset for 128 samples of 14 morphospecies. Blue numbers below nodes are estimated diversification dates with confidence intervals (blue bars). Posterior probabilities $(\mathrm{PP})$ are marked on nodes with an asterisk $(\mathrm{PP}=1.00)$. $\mathrm{Pli}=$ Pliocene, $\mathrm{Ple}=$ Pleistocene

five internodes (fig. 2, nodes B, D, E, G, and I) were weakly supported $(<70 \%)$, with weak phylogenetic signals at the nodes inferred from COI gene sequences alone. In particular, the relationships of LP I and LU I for node D were not clearly resolved. Unlike the NJ tree, LT I+II showed a sister relationship with LU
II (Jeju population) (Fig. 2, node H) and LT III clustered as a sister group to LU III in the ML analysis.

In the BItree(fig.3), Most nodes were strongly supported by high posterior probabilities $(>0.95)$, but others were weakly supported $(<0.95)$. The BI topology was more similar to 
the NJ topology than to the ML tree, but the relationships among Luciola substriata, LPA, and LT were consistent. The clade for the subgenus Hotaria was also strongly supported (fig. 3, node A). In the BI analysis, two groups of LPA formed a monophyletic group (fig. 3, node B). LT I+II showed a polytomy. LT III was a group sister to LU III as in the ML analysis.

\section{Molecular dating}

In a time-calibrated phylogram (fig. 4, tTable 2), the common ancestor of the subgenus $\mathrm{Ho}$ taria diverged from the most recent common ancestor of Luciola italica $\sim \mathbf{1 5 . 2 7} \mathrm{Ma}$ (18.84-11.89 Ma, 95\% higher posterior density [HPD]; fig. 4, node E). The subgenus $\mathrm{Ho}^{-}$ taria diverged from the common ancestor 13.19 Ma (16.60-9.87 Ma, 95\% HPD; fig. 4, node F). An ancestral lineage of LPA, considered the ancestor of the current population in Shikoku, Japan, diverged, followed by

TABLE 2 Divergence time estimates for nodes and corresponding 95\% highest posterior densities (HPD) of each divergence time estimate for nodes shown in fig. 4

Node Divergence Time (Ma)

Median $\quad 95 \%$ HPD

\begin{tabular}{lcc}
\hline A & 25.32 & $31.69-19.46$ \\
B & 2.53 & $3.36-1.72$ \\
C & 8.94 & $11.71-6.33$ \\
D & 2.51 & $3.53^{-1.55}$ \\
E & 15.27 & $18.84-11.89$ \\
F & 13.19 & $16.60-9.87$ \\
G & 11.26 & $14.33^{-8.35}$ \\
H & 4.38 & $5.62-3.16$ \\
I & 3.49 & $4.45^{-2.51}$ \\
J & 2.82 & $3.84-1.85$ \\
K & 2.69 & $3.62-1.83$ \\
L & 2.28 & $3.05^{-1.46}$ \\
M & 1.77 & $2.67-0.97$ \\
\hline
\end{tabular}

the split of another ancestral lineage of LPA $\sim 11.26$ (14.33-8.35 Ma, 95\% HPD; fig. 4, node G) from the common ancestor of LU, LP, and LT. We estimated that the radiation of LU, LP, and LT occurred during the late Miocene to Pliocene between 5.62 and $3.16 \mathrm{Ma}$ (mean 4.38 Ma; fig. 4, node $\mathrm{H}$ ). Five groups at node I diverged $\sim 3.49 \mathrm{Ma}$ (4.45-2.51 Ma, 95\% HPD). Interestingly, this divergence time coincided with the final disconnection of Japan from the Korean peninsula (3.5 Ma; Osozawa et al., 2012). The subsequent split between LT III and LU III occurred $\sim 2.82 \mathrm{Ma}(3.84-1.85 \mathrm{Ma}, 95 \%$ HPD; fig. 4, node J). The common ancestor of LU II (Jeju population) diverged from the most recent common ancestor of LP II and LT I+II $\sim 2.69 \mathrm{Ma}$ (3.62-1.83 Ma, 95\% HPD; fig. 4, node K). Subsequently, the ancestor of LT I+II diverged from the most recent common ancestor of LP II $\sim 2.28 \mathrm{Ma}\left(3.05^{-1.46} \mathrm{Ma}, 95 \%\right.$ HPD; fig. 4, node L). LT I and II diverged $\sim 1.77$ Ma (2.67-0.97 Ma, 95\% HPD; fig. 4, node M) from the most recent common ancestor. LU I and LP I diverged $\sim 1.99 \mathrm{Ma}\left(2.75^{-1.27} \mathrm{Ma}, 95 \%\right.$ HPD) from the most recent common ancestor. Terminal taxa diverged more recently at each locality between 1.12 and $0.05 \mathrm{Ma}$.

\section{Discussion}

DNA barcoding is a common tool for verifying morphospecies and investigating haplotype structures (Hajibabaei et al., 2007). The COI gene shows faster rates of evolution than those of nuclear genes and thus can provide greater resolution for analyses of morphologically similar species (Avise, 2004). The method is also useful for the detection of cryptic and/or pseudocryptic species with little morphological differentiation (e.g., Asiopodabrus in Cantharidae, Kang et al., 2012; Chrysochroa in Buprestidae and Denticollinae in Elateridae, Han et al., 2012, 2016). This approach is convenient owing to the availability of COI 
sequence data for comparative analyses; it is possible to explore the evolutionary history of the focal taxa using geologic events for the calibration of divergence times. In this study, we determined the phylogenetic relationships and evolutionary history of Hotaria species in Korea and Japan using a single genetic marker, COI, but including more LU and LP samples compared with previous studies (Kim et al., 2000; Choi et al., 2002, 2003). The results of our comprehensive analysis combining newly generated and previously published COI data contradict previous taxonomic descriptions of species in Hotaria.

Hotaria was originally established as a valid genus by Yuasa (1937) based on the type species Luciola parvula, endemic to Japan. However, the generic classification of Hotaria is still debated. In this study, the monophyly of Hotaria was strongly supported in all topologies (figs. 1-4) but we did not find evidence for the generic classification in our dataset. A robust phylogenetic study including numerous taxa in the tribe Luciolini is needed to resolve this issue. Therefore, Hotaria should be treated as a subgenus according to previous proposals (McDermott, 1966; Ballantyne, 1968).

We suggest a species complex, the Luciola (Hotaria) unmunsana species complex, including three morphospecies (LU, LP, and LT), which were genetically more closely related to each other than to LPA. This result is well supported by the monophyletic clustering with evidence for a recent divergence at $\sim 4.38 \mathrm{Ma}$ (5.62-3.16 Ma, 95\% HPD; fig. 4, node H). Surprisingly, the species complex had polyphyletic or paraphyletic lineages (figs. 1-4). This result provided an entirely new interpretation for the taxonomic assignments of the species based on a more accurate analysis of the evolutionary history, including geographical isolation and local population structures, than those in earlier studies (e.g., Kim et al., 2000; Choi et al., 2003). Unexpectedly, LU I and LP I, regarded as true $L$. $(H$.$) unmunsana and L$. $(H$. papariensis in previous studies (see Kim et al., 2004), were genetically more closely related to each other than to other groups, with genetic distances ranging from $1.54 \%$ to $4.17 \%$. This range can be explained by the genetic diversity due to local haplotypes in LU 1 and LP I, resulting from gradual divergence in different habitats (fig. 4, node $\mathrm{N}$ and fig. 5). We observed a similar phenomenon in other groups of LU, LP, and LT, suggesting that most local populations had limited gene flow and the observed genetic differentiation may be caused by limited dispersal related to apterous females, the short life span of males capable of flight, and nocturnal activity in each habitat. Most importantly, we identified a novel group, LU III (figs. 1-5), which included only the local populations collected in the Jeolla region, with genetic distances ranging from $2.02 \%$ to $4.77 \%$, and from $3.56 \%$ to $5.73 \%$ in comparisons with LU I and LP I; this can be considered a new cryptic taxon based on its allopatric distribution and the genetic divergence from other taxa. Subsequent divergence occurred in LT I+II, LP II, and LU II almost simultaneously, as evidenced by the short branch lengths in all analyses (figs. 1-4). We can assume that the L. (H.) unmunsana species complex recently diverged from the common ancestor by allopatric speciation, corresponding to geological events, such as the formation of mountains and rivers in Korea and discontinuous connections between Korea and Japan by repetitive sea-level changes during the Pliocene and Pleistocene. This hypothesis is supported by analyses of divergence times in this study.

Our divergence time estimates indicated that the common ancestor of LPA and LU+LP+LT (fig. 4, node G) diverged $\sim 11.26 \mathrm{Ma}$ (14.33-8.35 Ma, 95\% HPD) during the opening of the East Sea in the Miocene. At about $2 \mathrm{Ma}$ (13.15-11.26 Ma), LPA lineages settled separately only on the Japanese main islands, such as 


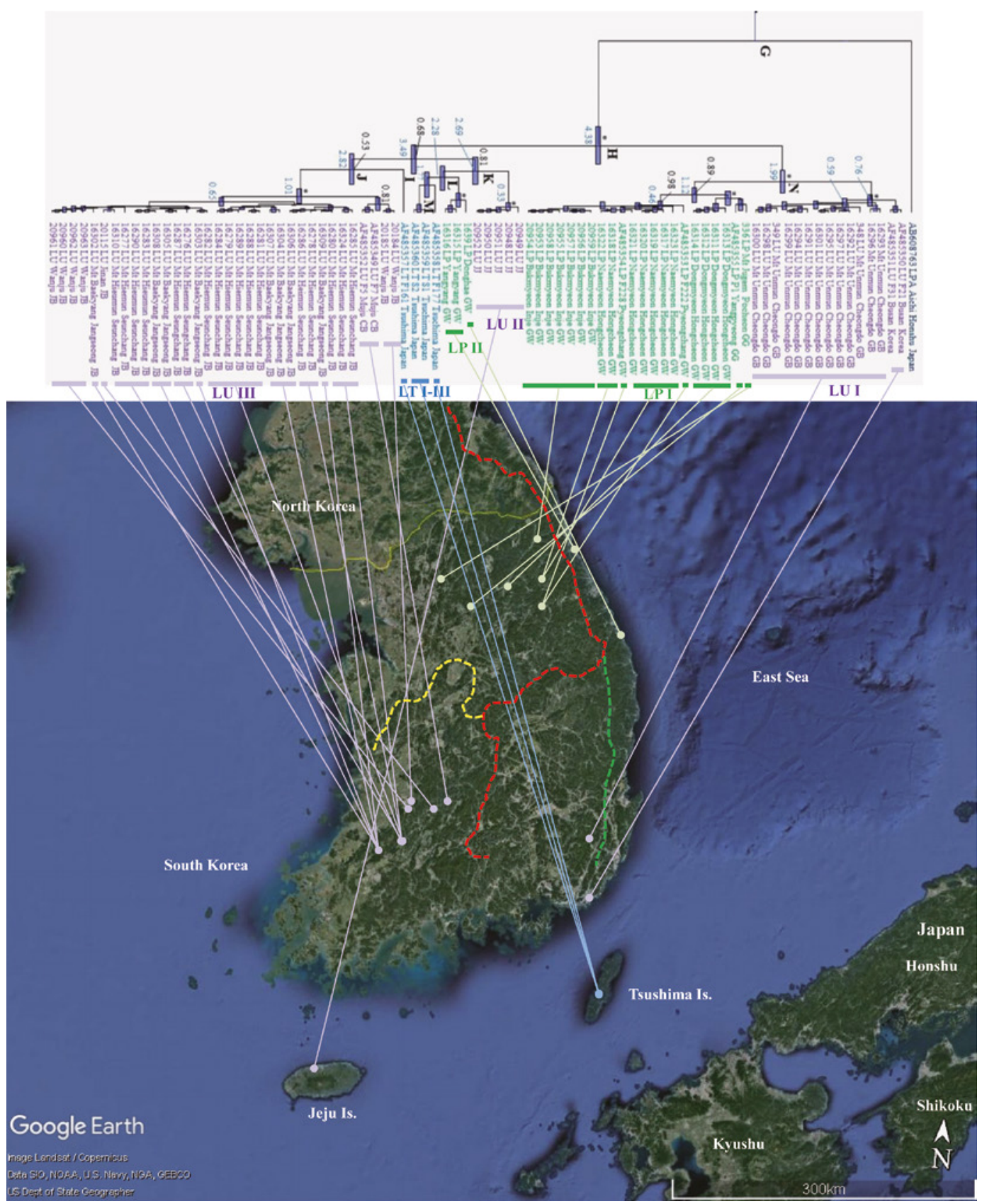

FIGURE 5 Distributional patterns (collection sites) for terminal taxa of Luciola unmunsana (LU), L. papariensis (LP), and L. tsushimana (LT) constructed using BEAST. Red dotted line indicates the approximate location of the "Bekdudaegan" mountains. Yellow dotted line indicates the approximate location of the "Hannam-Geumbuk Jeongmaeck" mountains. Green dotted line denotes the approximate location of the "Nakdong Jeongmaeck" mountains. The map was extracted from Google Earth. 
Honshu, Kyushu, and Shikoku. LPA includes two types distinguishable by body size (large and small), flash pattern of the mate-seeing male, genetic diversity, and location in Japan (Ohba, 1983, 1986, 2000; Suzuki et al., 1993; Ohba et al., 1995). Suzuki et al. (1993) suggested that the divergence between these two types of LPA and between LPA and LT occurred about $0.5 \mathrm{Ma}$ and $1.5 \mathrm{Ma}$, respectively. However, our results did not support the recent divergence time estimates obtained by Suzuki et al. (1993). We compared five COI gene sequences for LPA, including a sample (AB6o8763; supplementary table $\mathrm{S} 1$ ), which was collected from Aichi, Honshu, Japan (Oba et al., 2011), and four samples ( $\mathrm{AF}_{48561-4}$; supplementary table $\mathrm{S}_{1}$ ), which were collected from the same locality, Omogo, Shikoku, Japan (Choi et al., 2003). According to the previously known distributional patterns of these two types of LPA as mentioned above (Ohba, 2000; Suzuki et al., 1993), The Aichi and Omogo populations can be regarded as the large and small body types, respectively. Our results showed that the two groups of LPA were paraphyletic in three topologies (figs. 1, 2, and 4) with large genetic distances of $15.41 \%$ (fig. 1 , node $\mathrm{A}$ ); the estimated divergence times ranged from 16.60 to $9.87 \mathrm{Ma}$ (mean $13.19 \mathrm{Ma}$ ) and from 14.33 to $8.35 \mathrm{Ma}$ (mean 11.26 Ma), respectively, during the middle Miocene (fig. 4, node $C$ ). These results suggested that the two types of LPA currently found in Japan originated independently from two different ancestral lineages during the opening of the East Sea (Miocene epoch), refuting the hypothesis of recent divergence proposed by Suzuki et al. (1993). We consider that the two types of LPA may be pseudocryptic species, with genetic divergence but no appreciable morphological differences, except for body size.

The most recent common ancestor of LU+LP+LT (fig. 4, node $\mathrm{H}$ ) underwent biogeographical divergence 5.62-3.16 Ma (mean
4.38 Ma) on the Korean peninsula during the late Miocene to Pliocene. Despite evidence for the Miocene uplift of the Korean Major Mountains (called "Bekdudaegan") and its stems following the opening of the East Sea (23-9 Ma, Iijima \& Tada, 1990; 30-10 Ma, Jolivet et al., 1994; 15-5 Ma; Taira, 1990, 2001), little is known about the Pliocene and Pleistocene tectonic activities in Korea. It is difficult to infer the causal factors for the split of node $\mathrm{H}$ (figs. 4 and 5), e.g., physical barriers (such as mountains and rivers) or climate change. Therefore, further phylogeographic studies are needed including more local samples, especially in areas not included in this study. Interestingly, the divergence time estimate of 3.49 Ma (4.45-2.51 Ma, 95\% HPD; fig. 4, node I) for the initial split of the five groups is consistent with the final disconnection of Japan from the Korean peninsula, 3.5 Ma (Osozawa et al., 2012). LU III settled in an inland area around the Jeolla region. The subsequent allopatric radiations corresponding to nodes J, K, L, and M in fig. 4 may be related to sea-level fluctuations during the Pliocene and Pleistocene, forming land bridges connecting the southern part of the Korean peninsula with Jeju Is. and Tsushima Is. of Japan. In particular, the split of the common ancestor of LU II (Jeju population) between 3.62 and $1.83 \mathrm{Ma}$ (mean 2.69 Ma) is generally consistent with the Seogwipo Formation, stage I of the tectonic history of Jeju Island at 3.580.78 Ma (Yoon et al., 2004, 2014). In LT, three groups (LT I, II, and III) clearly originated on the Korean peninsula and colonized multiple times the Tsushima Is. of Japan. LU II (Jeju Is.) including a local population is consistent with a single colonization model. However, more sampling of Jeju populations is necessary owing to the possibility of multiple colonizations due to the repetitive connection between the mainland of Korea and Jeju Is. by land bridges during several glacial periods 
in the late Pliocene and Pleistocene. The current distribution of LP II is rather unexpected based on the sister relationship between LP II and LT I+II (fig. 4, node L) because the sampling sites of LP I and LP II were closest. However, there is a mountain barrier, "Bekdudaegan", which runs north to south in Korea (red dotted line in fig. 5). The two collection sites for LP II were on the eastern slope of the mountains, while the sites for LP 1 were on the western slope (fig. 5). LP II and LU I seem to be interrupted by the "Nakdong Jeongmaeck" mountains (brown dotted line in fig. 5). If Bekdudaegan and Nakdong Jeongmaeck act as biogeographic barriers, preventing the dispersal of LP I and LP II, the present distribution of LP II may be explained by range expansions toward northern South Korea along the eastern coast after the divergence of LT I+II at 2.28 Ma (3.05-1.46 Ma, 95\% HPD; fig. 4, node L). This scenario can be easily verified by an examination of other local populations along the eastern coast.

In summary, our results indicated that LU, LP, and LT are incipient species, including potential cryptic species resulting from recent allopatric speciation during the Pliocene and Pleistocene. We detected seven polyphyletic and paraphyletic groups for the three morphospecies using a DNA barcoding technique, without considerable morphological differences. This finding highlights the currently underestimated species diversity in Hotaria fireflies, which could not be detected using the traditional approach. However, this result inferred from a single mitochondrial locus will have to be supported by a concordant result when using nuclear genetic markers. Because our result showed that the sympatric sharing of geographically localized COI haplotypes, but genetically divergent lineages remains a possibility of mitochondrial introgression (Funk \& Omland, 2003) rather than demographic asymmetries, such as sex-biased dispersal (Toews \& Brelsford, 2012), and incomplete lineage sorting (Maddison, 1997). Furthermore, comparative ecological studies, such as studies of the flash patterns of mateseeking males and behavioral characters, are lacking for specific firefly species. More extensive sampling and investigations of ecological traits are required in further studies of allopatric speciation, the limited distribution of each group, and the multiple-colonization model proposed for LT to evaluate the hypotheses suggested by our analyses. The recognition of the exact species diversity is important to their conservation and management and then monitoring the distribution patterns of these locally separated groups should provide exciting insights into the history of speciation corresponding to the impact of the past tectonic events.

\section{Acknowledgements}

This study was carried out with the support of the Cooperative Research Program for Agricultural Science \& Technology Development (Project No. PJo12670012019), Rural Development Administration, Republic of Korea.

\section{Supplementary material}

Supplementary material is available online at: https://doi.org/10.6o84/mg.figshare.9901805

\section{References}

Amano, H., Matsui, M., Igarashi, M., Tanaka, M. \& Safrizal, E. (2013) Complete mitochondrial genome sequence of Luciola cruciate. Research reports, Fukushima National College of Technology, 54: 149-152. 
Avise, J.C. (2004) Molecular Markers, Natural History and Evolution. Sinauer Associates, Sunderland, MA.

Ballantyne, L.A. (1968) Revisional studies of Australian and Indomalayan Luciolini (Coleoptera: Lampyridae: Luciolinae). University of Queensland Press, Department of Entomology, 2, 105-139.

Bergsten, J., Bilton, D.T., Fujisawa, T., Elliott, M., Monaghan, M.T., Balke, M., Hendrich, L., Geijer, J., Herrmann, J., Foster, G.N., Ribera, I., Lilsson, A.N., Barraclouch, T.G. \& Vogler, A.P. (2012) The effect of geographical scale of sampling on DNA barcoding. Syst. Biol., 61, 851-869.

Bouckaert, R., Heled, J., Kühnert, D., Vaughan, T., Wu, C.H., Xie, D., Suchard, M.A., Rambaut, A. \& Drummond, A.J. (2014) BEAST 2: a software platform for Bayesian evolutionally analysis. PLoS Comput. Biol., 10, e1003537. doi:1371/journal.pcbi.1003537.

Choi, Y.S., Lee, K.S., Bae, J.S., Lee, K.M., Kim, S.R., Kim, I., Lee, S.M., Sohn, H.D. \& Jin, B.R. (2002) Molecular cloning and expression of a cDNA encoding the luciferase from the firefly, Hotaria unmunsana. Comp. Biochem. Physiol. B, 132, 661-670.

Choi, Y.S., Bae, J.S., Lee, K.S., Kim, S.R., Kim, I., Kim, J.G., Kim, K.Y., Kim, S.E., Suzuki, H., Lee, S.M., Sohn, H.D. \& Jin, B.R. (2003) Genomic structure of the luciferase gene and phylogenetic analysis in the Hotaria-group fireflies. Comp. Biochem. Physiol. B, 134, 199-214.

Doi, H. (1931) A new species of Luciola from Korea. Luciola unmunsana sp. Journal of the Chosen Natural History Society, 12, 54-55.

Doi, H. (1932) A new species of Luciola from Korea. Luciola papariensis sp. Journal of the Chosen Natural History Society, 14, 63.

Felsenstein. J. (1985) Confidence limits on phylogenies: an approach using the bootstrap. Evolution, 39, 783-791.

Folmer, O., Black, M., Hoeh, W., Lutz, R. \& Vrijenhoek, R. (1994) DNA primers for amplification of mitochondrial cytochrome c oxidase subunit I from diverse metazoan invertebrates. $\mathrm{Mol} . \mathrm{Ma}$ rine Biol. Biotechnol., 3, 294-299.

Funk, D.J. \& Omland, K.E. (2003) Species-level paraphyly and polyphyly: frequency, causes, and consequences, with insights from animal mitochondrial DNA. Annu Rev Ecol Syst, 34, 397-423.

Hajibabaei, M., Singer, G., Hebert, P.D.N. \& Hickey, D.A. (2007) DNA barcdoing: How it complements taxonomy, molecular phylogenetics and population genetics. Trends Genet., 23, 167-172. Han, T., Kang, T., Jeong, J., Lee, Y., Chung, H., Park, S., Lee, S., Kim, K. \& Park, H. (2012) Pseudocryptic speciation of Chrysochroa fulgidissima (Coleoptera: Buprestidae) with two new species from Korea, China and Vietnam. Zool. J. Linn. Soc., 164, 71-98.

Han, T., Kim, S.H., Yoon, H.J., Park, I.G. \& Park, H. (2019) Genetic variations of DNA barcoding region of bumble bees (Hymenoptera: Apidae) from South Korea. Mitochondrial DNA Part A, $30,30-42$.

Han, T., Lee, W.,, Lee S., Park, I.G. \& Park, H. (2016) Reassessment of species diversity of the subfamily Denticollinae (Coleoptera: Elateridae) through DNA barcoding. PLoS ONE, 11: e0148602. doi:10.1371/journal.pone.0148602.

Hebert, P.D.N., Cywinska, A., Ball, S.L. \& deWaard, J.R. (2003) Biological identifications through DNA barcodes. Proc. R. Soc. Lond., B, Biol. Sci., 270, 313-321.

Hendrich, L., Moriniere, J., Haszpruna, G., Hebert, P.D.N., Hausmann, A., Kohler, F. \& Balke, M. (2015) A comprehensive DNA barcode database for central European beetles with a focus on Germany: adding more than 3500 identified species to BOLD. Mol. Ecol. Resour., 15, 795-818. Hirashima, Y. (1989) A Check List of Japanese Insects. The Entomological Laboratory, Faculty of Agriculture, Kyushu University, the Japan Wildlife Research Center, Fukuoka. 
Hoang, D.T., Chernomor, O., von Haeseler, A., Minh, B.Q. \& Vinh, L.S. (2017) UFBoot2: improving the ultrafast bootstrap approximation. Mol. Biol. Evol., 35, 518-522.

Holder, M. \& Lewis, P.O. (2003) Phylogeny estimation: traditional and Bayesian approaches. Nat. Rev. Genet., 4, 275-284.

Hu, J. \& Fu, X. (2018) The complete mitochondrial genome of the firefly, Luciola curtithorax (Coleoptera: Lampyridae). Mitochondrial DNA Part B: Resources, 3, 378-379.

Iijima, A. \& Tada, R. (1990) Evolution of tertiary sedimentary basins of Japan in reference to opening of the Japan Sea. Journal of the Faculty of Science, The University of Tokyo, Section II, 22, 121-171.

Jolivet, L., Tamaki, K. \& Fournier, M. (1994) Japan Sea, opening history and mechanism: a synthesis. J. Geophys. Res., 99, 22237-22259.

Kalyaanamoorthy, S., Minh, B.Q., Wong, T.K.F., von Haeseler, A. \& Jermiin, L.S. (2017) ModelFinder: fast model selection for accurate phylogenetic estimates. Nat. Methods, 14, 587-589.

Kang, T.H., Han, T.M., Okushima, Y. \& Park, H.C. (2012) Integrative taxonomy of Asiopodabrus fragiliformis (Kang and Kim, 200o) (Coleoptera: Cantharidae) and its related species. Zootaxa, 3259, 1-33.

Kang, T.W. (2012) Cantharioids I (Arthropoda, Insecta, Coleoptera). Insect Fauna of Korea, 12, 1-102.

Kiesenwetter, H. (1874) Die Malacodrmen Japans nach dem Ergebnisse der Sammlungen des Herrn G. Lewis wahrend der Jahre 1869-1871. Dtsch. entomol. Z., 18, 241-288.

Kim, C.W. \& Nam, S.H. (1981) Present status of the Korean fireflies and their conservation. Bulletin of the Korean Association for the Conservation of Nature, 3, 311-328.

Kim, I., Kim, J.G. \& Jin, B.R. (2004) Phylogenetic relationships of the fireflies co-occurring in Korean and Japanese territories analyzed by luciferase and mitochondrial DNA sequence. Int. J. Indust. Entomol., 9, 155-165.

Kim, I., Lee, S.C., Bae, J.S., Jin, B.R., Kim, S.E, Kim, J.K., Yoon, H.Y., Yang, S.R., Lim, S.H. \& Sohn, H.D. (2000) Genetic divergence and phylogenetic relationships among the Korean fireflies, Hotaria papariensis, Luciola lateralis, and pyrocoelia rufa (Coleoptera: Lampyridae), using mitochondrial DNA sequences. Korean Journal of Applied Entomology, 39, 211-226.

Kim, J.G., Park, H.C., Lee, J.E. \& Jin, B.R. (2004) Korean Fireflies. Korean Society of the Fireflies.

Kimura, M. (1980) A simple method for estimating evolutionary rate of base substitutions through comparative studies of nucleotide sequences. $J$. Mol. Evol., 16, 111-120.

Kitamura, A. \& Kimoto, K. (2006) History of the inflow of the warm Tsushima Current into the Sea of Japan between 3.5 and o.8 Ma. Palaeogeogr. Palaeoclimatol. Palaeoeco.l, 236, 355-366.

Kurosawa, Y., Hisamatsu, S. \& Sasaji, S. (1985) The Coleoptera of Japan in Color, Vol. III. Hoikusha Publishing Co, Osaka.

Lewis, S.M. \& Cratsley, C.K. (2008) Flash signal evolution, mate choice, and predation in fireflies. Annu. Rev. Entomol., 53, 293-321.

López-Estrada, E.K., Sanmartín, I., García-París, M. \& Zaldívar-Riverón, A. (2019) High extinction rates and non-adaptive radiation explains patterns of low diversity and extreme morphological disparity in North American blister beetles (Coleoptera, Meloidae). Mol. Phylogenet. Evol., 130, 156-168.

Ma, C., Yang, P., Jiang, F., Chapuis, M., Shali, Y., Sword, G.A. \& Kang, L. (2012) Mitochondrial genomes reveal the global phylogeography and dispersal routes of the migratory locust. Mol. Ecol., 21, 4344-4358.

Maddison, W.P. (1997) Gene trees in species trees. Syst. Biol., 46, 523-536.

Maeda, J., Kato, D., Arima, K., Ito, Y., Toyoda, A. \& Noguchi, H. (2017) The complete mitogenome 
and phylogenetic analysis of Japanese firefly 'Genji Botaru' Luciola cruciate (Coleoptera: Lampyridae). Mitochondrial DNA Part B, 2, $5^{22-523 .}$

McDermott, F.A. (1966) Lampyridae, Pars. 9. In: W.O. Steel (Ed) Coleopterorum Catalogus, pp. 98-118. Junk, The Hague.

Minh, B.Q., Nguyen, M.A.T. \& von Haeseler, A. (2013) Ultrafast approximation for phylogenetic bootstrap. Mol. Biol. Evol., 30, 1188-1195.

Mu, F.J., Ao, L., Zhao, H.B. \& Wang, K. (2016) Characterization of the complete mitochondrial genome of the firefly, Luciola substriata (Coleoptera: Lampyridae). Mitochondrial DNA Part $A, 27,3360-3362$.

Nakane, T. \& Ohba, N. (1981) Observing and Breeding Fireflies. New Science Co, Tokyo.

Nakane, T. (1970) On the chantharoid coleopteran found in the islands of Tsushima (Insecta). Memoirs of the National Science Museum, Tokyo, $3,287-288$.

Oba, Y., Branham, M.A. \& Fukatsu, T. (2011) The terrestrial bioluminescent animals of Japan. Zool. Sci., $28,771-789$.

Ohba, N. (1983) Firefly fauna in Kanagawa Prefecture. Annual Report of the Yokosuka city Museum, 29, 17-19.

Ohba, N. (1986) Firefly Communication. Tokai University Press, Tokyo.

Ohba, N. (1987) Ecological dimorphism in Himefirefly, Hotaria parvula. The $47^{\text {th }}$ meeting of the Entomological Society of Japan, 32 .

Ohba, N. (1998) Biology of fireflies. Nature and Insect, Tokyo, 33, 2-6.

Ohba, N. (2000) Flash patterns and communication of the two ecotypes in Hotaria parvula. Science Report of the Yokosuka City Museum, 47, 1-22.

Ohba, N., Suzuki, H. \& Yamasak,i T. (1995) Luminescent pattern of Japanese fireflies based on computer analysis. Science Report of the Yokosuka City Museum, 43, 17-24.

Ohmiya, Y., Ohba, N., Toh, H. \& Tsuji, FI. (1995) Cloning, expression and sequence analysis of
cDNA for the luciferases from the Japanese fireflies, Pyrocoelia miyako and Hotaria parvula. Photochem. Photobiol. Sci., 62, 309-313.

Osozawa, S., Shinjo, R., Armid, A., Watanabe, Y., Horiguchi, T. \& Wakabayashi, J. (2012) Palaeogeographic reconstruction of the $1.55 \mathrm{Ma}$ synchronous isolation of the Ryukyu Islands, Japan, and Taiwan and inflow of the Kuroshio warm current. Int. Geol. Rev., 54, 1369-1388.

Papadopoulou, A., Anastasiou, I. \& Vogler, A.P. (2010) Revisiting the insect mitochondrial molecular clock: the mid-Aegean trench calibration. Mol. Biol. Evol., 27, 1659-1672.

Park, H.C., Kang, T.H., Kim, J.G. \& Shim, H.S. (2005) Lucidina kotbandia, a new species (Coleoptera: Lampyridae) from Korea. Entomol. Res., 35, 149-152.

Rambaut, A., Suchard, M.A., Xie, D. \& Drummond, A.J. (2014) Tracer vı.6. http://tree.bio.ed.ac.uk/ software/tracer.

Rizvanovic, M., Kennedy, J.D., Nogués-Bravo, D. \& Marske, K.A. (2019) Persistence of genetic diversity and phylogeographic structure of three New Zealand forest beetles under climate change. Divers. Distrib., 25, 142-153.

Ronquist, F., Teslenko, M., Mark, P., Ayres, D.L., Darling, A., Höhna, S., Larget, B., Liu, L., Suchard, M.A. \& Huelsenbeck, J.P. (2012) MRBAYES 3.2: efficient Bayesian phylogenetic inference and model selection across a large model space. Syst. Biol., 61, 539-542.

Saitou, N. \& Nei, M. (1987) The Neighbor-joining method: a new method for reconstructing phylogenetic trees. Mol. Biol. Evol., 4, 406-425.

Sim, H.S. \& Kwon, O.K. (2000) Patterns of the appearances and distributions of the genus $\mathrm{Ho}^{-}$ taria in Korea. Korean J. Ecol., 23, 211-215.

Sim, H.S., Kwon, O.K., Cho, D.H. \& Choi, J.K. (1999) Luminescent patterns of the firefly $\mathrm{Ho}^{-}$ taria papariensis from Korea. Korean J. Ecol., 22, 271-276.

Stanger-Hall, K.F., Lloyd, J.E. \& Hillis, D.M. (2007) Phylogeny of North American fireflies (Coleoptera: Lampyridae): Implications for the 
evolution of light signals. Mol. Phylogenet. Evol., $45,33-49$.

Suzuki, H. (1997) Molecular phylogenetic studies of Japanese fireflies and their mating systems (Coleoptera: Cantharoidea). Tokyo Metropolitan University Bulletin of Natural History, 3, 1-53.

Suzuki, H. (2001) Studies on biological diversity of firefly in Japan. Int. J. Indust. Entomol., 2, 91-105. Suzuki, H., Sato, Y., Fujiyama, S. \& Ohba, N. (1993) Genetic differentiation between ecological two types of the Japanese firefly, Hotaria parvula: an electrophoretic analysis of Allozymes. Zool. Sci., 10, 697-703.

Taira, A. (1990) Birth of Japan Islands. Iwanami Shoten Co. Ltd., Tokyo.

Taira, A. (2001) Tectonic evolution of the Japanese island arc system. Annu. Rev. Earth Planet. Sci., 29, 109-134.

Tamura, K., Peterson, D., Peterson, N., Stecher, G., Nei, M. \& Kumar, S. (2011) MEGA5: molecular evolutionary genetics analysis using maximum likelihood, evolutionary distance, and maximum parsimony methods. Mol. Biol. Evol., 28, 2731-2739.

Toews, D.P.L. \& Brelsford, A. (2012) The biogeography of mitochondrial and nuclear discordance in animals. Mol. Ecol., 21, 3907-3930.
Toussaint, E.F.A., Hall, R., Monaghan, T., Sagata, K., Ibalim, S., Shavergo, H.V., Vogler, A.P., Pons, J. \& Balke, M. (2014) The towering orogeny of New Guinea as a trigger for arthropod megadiversity. Nat. Commun., 4, 4001.

Trifinopoulos, J., Nguyen, L.T., von Haeseler, A. \& Minh, B.Q. (2016) W-IQ-TREE: a fast online phylogenetic tool for maximum likelihood analysis. Nucleic Acids Res., 44, W232-W235.

Wang, K, Hong, W., Jiao, H. \& Zhao, H. (2017) Transcriptome sequencing and phylogenetic analysis of four species of luminescent beetles. Sci. Rep., 7, 1814.

Yoon, S., Jung, C.Y., Hyun, W.H. \& Song, S.T. (2014) Tectonic history of Jeju Island. Journal of the Geological Society of Korea, 50, 457-474.

Yoon, S., Yi, S., Bak, Y.S., Jung, C.Y. \& Lee, E.H. (2004) Calcareous nannofossils and diatoms from the groundwater monitoring wells in the eastern part of Jeju Island.Journal of the Paleontological Society of Korea, 20, 99-119.

Yuasa, H. (1937) Description of a new genus of the family Lampyridae (Coleoptera). Kontyû, Tokyo, 11, 107-109.

RECEIVED: 11 JUNE 2019 | REVISED AND

ACCEPTED: 24 SEPTEMBER 2019

EDITOR: D. COPILAS-CIOCIANU 